\title{
Promoting Well-Being of Children at School: Parental Agency in the Context of Negotiating for Support
}

\author{
Teija Koskela* \\ Faculty of Education, Department of Teacher Education, University of Turku, Turku, Finland
}

\section{OPEN ACCESS}

Edited by: Ariane Paccaud,

Zurich University of Teacher Education, Switzerland

Reviewed by:

Päivi Rautava,

Turku University Hospital, Finland

Serge Ramel,

Haute École Pédagogique du Canton de Vaud, Switzerland

*Correspondence:

Teija Koskela

teija.koskela@utu.fi

Specialty section:

This article was submitted to

Special Educational Needs,

a section of the journal

Frontiers in Education

Received: 12 January 2021

Accepted: 29 March 2021

Published: 26 April 2021

Citation:

Koskela T (2021) Promoting Well-Being of Children at School:

Parental Agency in the Context

of Negotiating for Support.

Front. Educ. 6:652355.

doi: 10.3389/feduc.2021.652355
This study describes how parents experience their role in enhancing the well-being of their children and what this reveals about parental agency in the context of collaborations between home and school. In Finland, schools are among the most important environments for delivering services to children. The goal of this study is to bring into focus the parental dispositions in multi-agency interactions based on their experiences and to make sense of both their successes and the barriers they face. The Finnish education system aims to develop itself according to the inclusive principles. However, the inclusive school culture is still a work in progress. The parental agency and positions in collaboration with school personnel are ambivalent, and there are several assets and barriers that affect their ability to participate fully in discussions about the well-being of their children at school. In this article, the parental positions are connected to situations where they negotiate the process of collaborative planning of support for the learning and well-being of their children in the school environment. Participants are 13 mothers and one couple, mother and father. Their experiences are analyzed qualitatively via interviews and the concept of agency, a sociological concept that refers to the mutual relation between a culture or structure and the opportunities of human agents to interact within the given contexts. The results reveal qualitative differences in the experienced parental agency. The parental agency is connected to the given opportunities, and the key role in making the agency possible in the schools is given for the teachers. Behind everyday practices, there are deeper questions about the parental positions and their value in collaboration.

Keywords: parental agency, school, inclusive education, Finland, qualitative research

\section{INTRODUCTION}

This study explores parental agency in situations where parents negotiate and plan support with school personnel for their child. The schools play a significant role in supporting the well-being of children. The parental voices should be heard when processing and planning support for their children at school. An example of the planning process is a negotiation concerning individual educational plans (IEPs) of students (Tucker and Schwartz, 2013). In general, it is important for parents to play active roles in the learning of their children. Effective parental involvement improves the academic performance, well-being (Hartas, 2008), and school attendance of students (Michael et al., 2007). The parent-teacher relationship is important to the well-being of a child, especially when the child needs support for self-regulation and behavioral challenges (Rautamies et al., 2016).

In inclusive education, all parents are valuable members of the school community. Shared understanding of responsive learning environments and supportive processes are important 
implications of inclusive school culture (Kozleski and Waitoller, 2010). In Finland, both the national core curriculum (Finnish National Agency for Education [FNAE], 2016) and legislation provide guidelines on how to take the well-being of children into account during school days and how to encourage parental participation. Participation in welfare planning at the political level has recently been highlighted as an emancipatory practice; however, there are conflicts between individual narratives and political texts and guidelines: the will of political narratives is difficult to be recognized in individual experiences, especially for vulnerable groups of people who have minimal decisionmaking power and who are most affected by those decisions (Knibbe and Horstman, 2019).

In this sense, the role of parents in negotiations with schools is not yet evident. There are several obstacles to parental participation, such as conflicting understanding of the rights of children, parents, and teachers (Rogers, 2007). Political discussions and debates about democracy and welfare constitute complex collections of fragmented small-scale and individual stories, and individuals are seeking the meaning of their own experiences and possibilities in this whole picture (Knibbe and Horstman, 2019). The unsolved contradictions between theory, policy, and practice affect the everyday lives of families (Rogers, 2007). There are several structural issues associated with promoting inclusive school cultures. In teacher education, for example, there is a very narrow place for discussion of culture and how to transform it in schools through negotiations (Kozleski and Waitoller, 2010).

The parental ability to affect the everyday experiences of their children at school is occasional, complex, and contradictory. Schools should promote practices that celebrate success, empower parents to take action, and share visions (Bryan and Henry, 2012). Thus, efforts to support school every day for their children also cause parents to feel powerless and excluded (Hein, 2017), and their experiences varied, from being proactive to hindered (Rautamies et al., 2019). In research concerning the multi-agentic approach supporting students, the parental position is often described as an object of a multi-agency team, and the real agency and voice find place by professionals in the team, not given to the parents (Barnes, 2008).

It is important to recognize that strong parental agency can be beneficial to everyday work performed by schools. We need information from schools and parents to develop teacher education to improve inclusive practices for diverse learners in schools. This study examines the parental agency in negotiations with schools concerning the support needs of their children within an inclusive education framework and gives a voice to parents. The aim is to declare how the parental experiences in interactions can be interpreted in terms of an experienced agency. Thus, the parental agency and voice are made visible.

\section{Inclusive Framework - Parents as Collaborators}

Inclusive education is usually presented by political documents, such as the UNESCO Salamanca statement and the 2030 Agenda for Sustainable Development Goals (United Nations, 2015). It is based on the rights of the disabled people and children and is fundamentally grounded in the Declaration of Human Rights. It should be understood more as a process than a state (UNESCO, 2018).

In an inclusive educational culture, the basis of cooperation is a confidential and good relationship between schools and the parents (Kozleski and Waitoller, 2010). Inclusive culture in schools and its implications for everyday work are founded on the principles of democracy (Mitchell, 2012). Inclusive culture respects differences and encourages engagement to provide all pupils with access to education (Ainscow, 2014). In inclusive environments, parents are recognized, respected, and active members in the classroom and school community (Mitchell, 2012), and teachers value parental involvement (Okkolin et al., 2018). Parental cooperation is also considered to be an effective inclusive practice (Mitchell, 2014), and the nonparticipation of parents is seen as a barrier to inclusive education (Kozleski et al., 2009).

According to the European Agency for the Development of Special Needs Education (EADSNE), working with others is seen not only as a practice but also as a value in competencies of teachers (European Agency for Development in Special Needs Education [EADSNE], 2011). Furthermore, a well-functioning, inclusive school community can be seen as a resource to parents in terms of supporting the well-being of their children (Illsley and Redford, 2005; Koskela et al., 2020). Similarly, teachers can see parents as a resource in terms of solving problems, cooperating, and supporting their work (Okkolin et al., 2018; Väyrynen and Paksuniemi, 2020). There is a need for an epistemological shift to make understanding of environments and local cultures of schools more visible in the everyday decision-making of teachers (Payne and Zeichner, 2017) and use interactive structures to support the well-being of both students and families with multiprofessional personnel from schools (Ainscow et al., 2006).

In a study by Runswick-Cole (2008), parents identified attitudinal barriers, hostile school cultures, and inflexible teaching styles as obstacles to successful inclusive education. There are also barriers to parental participation. When teachers position themselves as experts, families tend to be in a lower position in the hierarchy and discussions (Kozleski and Waitoller, 2010). However, the role of teachers is crucial in promoting inclusive education in schools (Savolainen, 2009). In addition, all school personnel can promote their own decisions to redefine inclusive practices in the school context (Ainscow et al., 2006). At the same time, teachers have the ability to change school culture if needed (Kozleski and Waitoller, 2010). It is important to encourage parents to challenge the decisions of authorities and professionals, as well as environments and school cultures if they are to change (Thomas, 2013). In this sense, the interpretation of inclusive education of school culture as a multiagentic community breaks the traditional framework of power by creating more space for parental voices.

\section{The Concept of Agency}

Agency is a widely used concept in sociology and is connected to theories of practice, and the stratification model of intentional and rational action (Giddens, 1984). It is understood in relation 
to cultures and structures (Archer, 2010). It is seen as the intentional content of ambition, personal ability, or quality, and it is discussed in relation to questions about its position between individuals and structures as well as the interplay between agency and context (Archer, 2010). In this research, agency is based on relational and transactional relations, and as such, it refers to free will in modern, postmodern, and transmodern society, with a need or a right to express oneself and to take initiative in his/her own processes. It represents attempts at intentional and meaningful actions with aspirations for consequences (Grillitsch and Sotarauta, 2020).

Biesta and Tedder (2007) approached agency from a lifecourse perspective. For parents, parental agency is not a choice, and the life-course perspective better gives the suitable relation to the given, specific situation of their child. Lucas (2019) connected the parental agency as individuals to a multi-agency environment and revealed that the parental agency is limited and that parents struggle to establish a positive and active role for themselves. Parents have to repeatedly renegotiate their roles (Tveit, 2009). According to Biesta and Tedder (2007), individuals can achieve more or less agency depending on their own engagement and also recognize resources in the context at hand. In this study, agency is understood as an ecological phenomenon. Edwards (2017) highlighted the dynamic and intertwined relation between agency and cultural practices to clarify the meaning of organizational changes in a way that enables criticism of the present and makes it possible to create new visions of the activity. Agency is based on the past, happens in a certain moment, and aims for the future (Biesta and Tedder, 2007). It is difficult to understand agency without taking into account the context and social environment, and personal life course also plays an important role. Furthermore, agency is connected to adult learning processes in the context of professionality (Biesta and Tedder, 2007; Eteläpelto et al., 2013; Edwards, 2017), but learning in the parental positions as active agents has not yet been widely covered.

According to Emirbayer and Mische (1998), the conception of agency is based on a chordal triad of iterational, projective, and practical-evaluative dimensions of agency. First, the iterational dimension lies in the earlier experiences of past interactions of actors. It concerns the schematization of social experience, and those schemas "consist in the interpretation of mental categories, embodied practices, and social organization" (Emirbayer and Mische, 1998, p. 975) as social environments. Experiences are notable in transactions when an actor is, for example, directing selective attention in a flow of situations. Second, the projective situation focuses on future possibilities. According to Emirbayer and Mische (1998), "an imaginative engagement of the future is also a crucial component of the effort of human actors" (p. 984). It aims to promote purposes and goals and can be described in terms of hopes, dreams, aspirations, and fears. In this dimension, agency is based on the hypothesization of experience. The third part of the triad is the practicalevaluative dimension that focuses on the present moment. All decisions, judgments, and choices have to be made in reality in certain contexts and circumstances. There are confusing contradictions and emergences to face. Designation of the practical-evaluative dimension is connected to practical wisdom, prudence, application, and intelligent improvisation. Agency in this dimension is understood as contextualization located in social experience (Emirbayer and Mische, 1998).

\section{Context of the Study}

In the Finnish educational system, one of the leading ideas is to give all citizens the opportunity to educate themselves. Education, including study materials and daily warm meals for all students, is free of charge in K-12 education. Supportive elements, e.g., school transportation (when needed), are also free. Therefore, education as a system is strongly connected to the well-being of children (Koskela et al., 2020).

The educational system in Finland is seen as rather inclusive (Halinen and Järvinen, 2008; Chong, 2018), and the latest National Core Curriculum for Basic Education (NCCBE) guides schools to make all developments in ways that promote inclusive education (Finnish National Agency for Education [FNAE], 2016). One aim is to deliver national consistency in educational policy by unifying institutional structures in the country and bringing together students with diverse backgrounds and needs (Chong, 2018). However, the text refrains from using the concept of "inclusive education" (Väyrynen and Paksuniemi, 2020), and it is explicitly mentioned only once: "The development of basic education is guided by the inclusion principle" (Finnish National Agency for Education [FNAE], 2016, p.19). Every year, there are only fewer students attending special schools. There are, however, special groups in mainstream schools. In 2016, among students receiving special support, $11.0 \%$ were at special schools; in 2019 , the number had dropped to $6.9 \%$, while the percentage of special-needs students in mainstream education increased from 18.9 to $22.5 \%$ (Official Statistics of Finland [OSF], 2020). The other students receiving special support were in special groups in mainstream schools, and participation in mainstream class teaching was flexibly organized. Among receivers of special support, the group of students who participated $21-99 \%$ of yearly teaching hours in the mainstream classroom increased from $28.8 \%$ in 2016 to $30.3 \%$ in 2019 (Official Statistics of Finland [OSF], 2020).

There is still a gap between inclusive education as a normative goal and its implications. The legislation exits, and its execution is still proceeding. Conceptually there are still reasons for using expressions of integration (see Hotulainen and Takala, 2014) instead of the concept of inclusion. Previous research has confirmed the differences in results and conclusions between sources of information. According to students, the inclusive agenda has not yet changed pedagogy or the learning environment enough to accommodate diverse learners (Vetoniemi and Kärnä, 2019), and when teachers are asked, there are several pedagogical solutions in use (Okkolin et al., 2018). However, parents see differences between schools in terms of well-being; for example, studying in the same school as their neighborhood peers improves the self-worth of children (Hotulainen and Takala, 2014).

The parental voice in research is relatively narrow. Most of the research concerning collaboration in Finland is written based on the points of view of teachers, and the bulk of the literature 
seems to report several, partly contradictory conclusions. Parents, in general, can be seen as overly demanding partners from the point of view of teachers (Takala et al., 2012), whereas parents report a clear hierarchy during discussions and see themselves as laymen and teachers as experts (Böök and Perälä-Littunen, 2015). According to Rogers (2007), parental experiences are negative when their children are in mainstream classrooms. However, the majority of parents have rather positive attitudes toward inclusive education and having children with special needs in the same classrooms as other students when possible, but they had concerns about emotional development, individualized instructions, and the availability of services in inclusive contexts (de Boer et al., 2010).

Teachers credit parents as valuable collaborators (Okkolin et al., 2018). According to teachers, parents are a diverse group, and there is a need not only to identify differences between parental groups but also to adjust the working methods of schools and teachers (Äärelä et al., 2018). However, there are inequalities between home and school, and parents have to fight to support the well-being of their children in the context of education (Honkasilta et al., 2015).

The support provided in the three-tiered system, according to the idea of response to interventions, the teacher is relatively autonomous, and the aim is to organize support for students as close as possible to their own class group (Björn et al., 2016; Engelbrecht et al., 2017). In Finland, there is no legislation-based need to have a medical diagnosis to have support in education. Legislation gives school authorities and municipalities the right to make decisions about the support for students by pedagogical conclusions, but in decision-making, there is a need to work in multidisciplinary teams, there must be members from health care or social work, and the voices of children and parents should be heard (Basic Education Act [BEA], 2010). In yearly negotiations, the level and methods used to support the well-being of children have to be considered as well.

\section{MATERIALS AND METHODS}

Data were collected from interviews with 14 parents between 2016 and 2018. Participants were found in the own networks and organizations of parents via snowball sampling. The firststage participants were invited to interviews and asked to help us find additional relevant participants (second-stage participants). Based on the invitations, participants approached the researcher. The participation was voluntary, and all the participants were informed about the research by receiving a written informative leaflet before the interview. Parents gave their verbal consent at the beginning of the interview. The process followed the instructions of the Finnish National Board on Research Integrity (2009).

Although the invitation to participate was addressed to parents, all the participants were mothers, except in one case, where both parents, mother and father, were interviewed. This seems to be a common occurrence in this research area (see, e.g., Griffiths et al., 2004; Tucker and Schwartz, 2013; Koskela et al., 2020). All participants, at the time of the interview, had at least one child in compulsory education (basic school) who, according to the parents, needed support at school. All participants were Finnish speakers. The participants were free to decide what information they wanted to tell about their children. Some parents decided not to tell about some details. The diagnoses of children were not asked, but some parents chose to discuss them in the interviews. A description of the participants can be found in Table 1.

The locations of and/or technological devices used for the interviews were negotiated with the participants. Face-to-face interviews were conducted at, for example, workplaces of parents, local libraries, and university classrooms. Otherwise, interviews were conducted via phone or an online video application. The interviews were recorded with a separate and local device of an interviewer.

The interview protocol was relatively open. Thematically, the participants were asked about the educational and supportive needs of their children, how they participated in the planning process, and what kinds of experiences they had had over the years in this process. Parents were encouraged to discuss whatever point of view they considered important. They were asked to give examples and to describe their feelings and thoughts. As a limitation, it is important to note that their descriptions were about experiences and events that had transpired before the interviews were conducted. Although the content of the discussions was decided by the participants, some moments in interviews were deeply emotional. Some participants cried, showed frustration, and/or became angry when relaying their experiences. After the interview, some participants expressed their happiness for having had the opportunity to discuss their experiences.

Recordings were transcribed verbatim, anonymized, and then organized according to expressions pertaining to agency. NVivo was used to organize the interview data, but the nodes were made manually.

The analytical framework in this study is a combination of the triad described by Emirbayer and Mische (1998) and the time dimensions (past-present-future) described by Biesta and Tedder (2007). Those three dimensions and, in addition, the context of agency were searched deductively in interview data. In each category, the aim is to describe and further categorize inductively the qualitative variation of experiences. The approach is phenomenographical, including the ontological assumption of a shared reality in which experiences of individuals are different and the epistemological assumption of conception and experience as such is told without taking into account what really has happened, the so-called second-level point of view (Marton and Booth, 1997; Sin, 2010). Furthermore, parents are not categorized as individuals, but as experiences. There are many teachers and contexts, and each parent has had many qualitatively different experiences. All parents had positive and negative experiences, and the complexity of each situation is high, so a simple typology of parents is unnecessary (see RunswickCole, 2008).

There is no objective information about meetings, such as video recordings to compare the interpretations and experiences of parents to some idea of objective observation. This research 
TABLE 1 | Participants.

\begin{tabular}{|c|c|c|c|c|}
\hline $\begin{array}{l}\text { ID-number and } \\
\text { participant }\end{array}$ & Child & Need of support & Diagnosis, if mentioned & Location and tier* \\
\hline (1) Mother & Son, 7 th grade & Behavioral & No information & Mainstream, tier 2 \\
\hline (2) Mother & Son, 4th grade & Behavioral & $\begin{array}{l}\text { Attention deficit hyperactivity } \\
\text { disorder (ADHD) }\end{array}$ & Mainstream, tier 2 \\
\hline (3) Mother & Son, 8th grade & Multiple needs & Mental disability & Special school, tier 3 \\
\hline (4) Mother & Son, 2nd grade & Visual observing & Visual defect & Mainstream, tier 3 \\
\hline (5) Mother & Son, no information of current grade & Communication and fears & Linguistic difficulties & Mainstream, tier 2 \\
\hline (6) Mother & Son, 3rd grade & Behavioral & No specific diagnose & Mainstream, tier 3 \\
\hline (7) Mother & Two sons, 5th and 6th grades & Multiple needs & $\begin{array}{l}\text { Autisms, learning difficulties, } \\
\text { mental disability }\end{array}$ & Special group in mainstream school, tier 3 \\
\hline (8) Mother & Son, 3rd grade & Behavioral & No specific diagnose & Mainstream, tier 1 \\
\hline $\begin{array}{l}\text { (9) Mother and } \\
\text { father }\end{array}$ & Daughter, 3rd grade & $\begin{array}{l}\text { Vocabulary, speaking, reading, } \\
\text { writing }\end{array}$ & $\begin{array}{l}\text { Linguistic difficulties and } \\
\text { dyslexia }\end{array}$ & Special group in mainstream school, tier 3 \\
\hline (10) Mother & No information & Learning difficulties & No information & Mainstream, tier 2 \\
\hline (11) Mother & Daughter, no information & $\begin{array}{l}\text { Multiple needs, such as eating, } \\
\text { communication, and speaking }\end{array}$ & No information & Special school, tier 3 \\
\hline (12) Mother & Son, 1st grade & Behavioral & ADHD & Mainstream, no information of tier \\
\hline (13) Mother & Daughter, 4th grade & Multiple needs & Several diagnoses & Mainstream, no information of tier \\
\hline (14) Mother & Son, 5th grade & Multiple needs & Mental disability & Special group, mainstream school, tier 3 \\
\hline
\end{tabular}

*Tiers according to the RTI model (see Björn et al., 2016): tier 1 = general support, tier 2 = intensified support, and tier $3=$ special support.

focuses on the discussions of parents on their experiences-which are valuable and real-and they are described in the ways and via the concepts and words that they chose themselves.

\section{RESULTS}

\section{Context of Collaborative Planning}

According to the interviews with parents, opportunities for collaboration were various, including IEP meetings (which are mentioned and demanded in the NCCBE); other multiprofessional or evaluative meetings; shared evenings for all parents; and occasional informative messages by phone, paper notes, and email or electronic communication tools. The ways and tools of mutual interaction were given and decided at school without negotiating with parents, and they varied between teachers.

From the perspectives of parents, the most important contextual aspect was the teacher responsible for a group of students: primary education teacher, class teacher, or group tutor. The attitudes of parents toward teachers and their actions led the narratives in all episodes. A change of teacher was usually the breakpoint in the continuum of experiences. There were many descriptions and interpretations of hopes, threats, possibilities, worries, and actions associated with a change of teacher. A change of teacher led to the change of the whole context.

Acknowledgments of the remarkable roles of teachers were present in all interviews. The teacher at hand is the key person who leverages the position of a parent. In this sense, the parental agency is more dependent on social contexts as a structure of networking and especially on relations between persons than on the written documents or structure of context in a school unit. Based on the parental experiences, there are many networks of different dynamics, maneuvers, and aims within the same school unit.

Interview (I)-3: It depends so much on the teacher and teachers interests. It [the IEP meeting] can be like "reading through the paper" situation [...], but if there is a teacher, who at first is telling about my child and how the teacher is getting along with the child and other things about school every day, some general examples, then the discussion about paper [IEP] is more about sharing experiences. It is incredible how much the situation is dependent on how the teacher is leading the process and, on the other hand, how parents adapt themselves to the style of the teacher.

During the whole interview, all the data were connected to the question of the teacher as a person and the wide autonomy of teachers. As an example, according to the descriptions of parents, teachers are able to make individual decisions either to listen or not to listen to the parental voices. If the teacher is not willing to encourage the participants in a discussion, it is difficult for all other participants. The presumed leader in discussions is the teacher.

I-11: The teacher is the central person; the teacher maintains interactive discussion and is surely the one who creates a kind of safe and respectful atmosphere for collaboration.

While trying trials to find their positions in diverse contexts, parents used not only their own earlier experiences but also their networks. Networks gave parents important information on how to act, what to demand as a right, and how to protect themselves and their children from unpleasant solutions.

Until it was not obvious to have the role of respected peer in negotiation, parents used different strategies based on their experiences. Parents have to learn their positions to hold their agency without any instructions. In the interview, data had no 
descriptions of instructions telling parents what to do or how to do it. The only way to learn how to be a parent in this kind of situation is by negotiating with teachers and other experts as representatives of educational institutions-i.e., trial and error. In these data, there were no accounts of school personnel telling parents their rights or helping them to find their role in a new kind of discussion. Parents, however, found their own networks important to reflect on discussions. In some cases, they brought someone, such as grandparents, with them for discussions at the school to help themselves manage challenging situations.

Every parent had positive experiences with certain teachers in certain contexts. They all had experienced, at some point when their children were at school, situations in which it was possible to participate, be agentic, and collaborate, which led to positive outcomes. Descriptions of such situations were qualitatively similar. All parents had also experienced many conflicts and agency-limiting situations.

\section{The Iterational Dimension of Agency-Interpretations of the Past}

Parents interpreted social transactions as embodiments of school practices and schools as social organizations. Parents interpreted and described the explicit behavior of teachers, relations between other agents in multiprofessional meetings, and communication between actors as meaningful parts of the process of understanding their own positions as actors in those practices and in their specific contexts or school organizations. The important things are to clarify parental agency in the process of decision-making concerning their children and, in an inclusive framework, to participate in the discussion of school culture as a member of school society; they realized what their space was to be initiative and deliver agency.

I-7: Well, in John's case, such as behavioral things and everyday routines, they clearly really try to use those methods with which I try to provide them.

I-8: And my suggestions had no gain. Like it was always the feeling that teachers know what to do at school-that feeling like they really did not want to listen to my suggestions. It was annoying.

The described practices as experienced by parents were versatile and fragmented. Parents had to recognize how wide the implication gap is between one individual teacher and written local and national norms in a specific context, school (as an organization), and actual practices.

I-5: [T]hen the teacher called me and told that they had a multiprofessional welfare team meeting, and they had discussed there that the intensive support has been taken away from my child [...] and you can discuss it at home with your husband, and I said that there is no need to discuss and the support is not going to stop. [...] And then [in the meeting], the special needs education teacher listened the whole time [to the discussion between the child, parent, and teacher] and asked, if I had time to stay a while after meeting. And I went, and the special need education teacher said immediately that the intensified support will not be taken away during basic education.
Several things complicated the situation described in the quotation. The interpretation of operations model at school was unorganized and process drift more by accident as designed. There were problems compared to norms. First, the multiprofessional team should not discuss individual issues without the permission of the child and parents. There has to be consent. Furthermore, the parents should have had better information earlier. Now, parents have experience with a situation in which they have not heard in time of preparation. The idea of revoking intensified support was unexpected, strongly against the will of parents and their understanding of the wellbeing of their child at school. In addition, the idea was not discussed with school personnel; the special education teacher had thought differently, did not contribute to the meeting, and was only consulted later.

Parents found differences between teachers, even in the same school-sometimes in discussions with other parentsbut usually, they had different experiences with several teachers. Parents compared, for example, choices about physical meeting locations. They generated interpretations about how they were located in the classroom and where the meeting took place.

I-7: Like in Steve's [pseudonym] IEP meeting, we were all seated around an oval table. I was on the other side and the school assistants and teachers were on the other, and when Steve came he was at the head/end of the table with another assistant. That setup gave me a feeling that we are all here equally to talk about things. Then, at John's [pseudonym] IEP, we were in a classroom. On the other hand, it is good to see where the child is working, but it could have been better if we had a table to share things together. Now we, me with John, were sitting at pupils' work tables and the teacher was at the front behind the teacher's desk. And the feeling was different. There was a clear split, like who is going to lead discussion, who controls the situation, and who decides what we are going to discuss. That I am like on the level of a child and another is like adult, like a teacher and professional. I think this kind of setup could be developed.

When parents found themselves in erratic situations, interpretations of their agency were severely limited. The school manifested the use of power by using the numerous persons of expertise and professional language and the effect of overtaking by situation. Some of the experienced meetings in interview data represented a manifestation of using institutional force and power and positioned parents in a powerless role.

I-6: I thought that we have the last crise [sic] situation to discuss at school and then, surprisingly, I recognize, I was there alone, my husband was not able to join at that moment, and from the school personnel there were the special education teacher, headmaster, school aides, class teachers, and whoever. There were a lot of people, and I was alone, and it was terrible and confusing to be in that situation.

I-10: There are doctors and psychologists and teachers, and somehow it turned to feeling that they are... well, the parent is really alone in the situation, [...] and then some doctors, psychologists, are highly educated and there is a need to be really concentrated that speaking is not... The language is something that a parent cannot understand. 
On the other hand, in every interview, there were references to the availability of teachers. As a practice to promote trust between parents and school personnel, the clear information of contact area between parent and at least one teacher is crucial. It seems to be important to understand local schools as coherent organizations. Parents understood to be treated as respected adults when they had the possibility to be active in the processes concerning their child. The processes and the course of action were clear. When they got answers, parents did not report being confused.

I-4: It is the best way-to go and talk face to face-to avoid all that... Like not to misinterpret the other person, to avoid misunderstandings, and to get at least some kind of answer immediately.

I-9: If I make contact with the school, the teacher-there is a need to discuss something-the meeting is organized quickly. Usually the meeting takes place during a long break [during the school day]. We take a moment and discuss those things.

When parents had no information about the teachers of their children, and when they did not know how and when to make contact with each teacher, taking initiative was difficult. When there were difficulties in reaching and speaking with teacher, there was a lot of tension in certain interactions.

Interpretations are distinctive in situations where the parental experiences reflect a culture of respect and good organization. Parents know exactly whom to contact and how processes are run. They get answers to their questions, and there is no confusing information. Parents felt empowered and accepted, with all of their feelings, and both challenges and successes were shared. The understanding of the well-being of children is openly discussed and coherent.

I-14: It is always so nice to be there. The teacher knows that I easily get tears in my eyes and can read me well and tells me in a positive way about Michael's [pseudonym] things, like challenges, which I know, but always if there is some, even the smallest development, the teacher remembers to tell me.

\section{The Projective Dimension of Agency}

In the projective dimension, the parental voices are united. The qualitative differences between their descriptions of aims, hopes, and fears are few and narrow.

The aim of collaborative negotiation, according to the parental point of view, was clearly more about the well-being of their children than in learning. Especially the relation between teacher and child was important. Good relation was described as a central aim and hope. Parents had also fears in case they believed teacher-student relationship was problematic. They wanted teachers to be fair and flexible. They hoped that teachers would be positively interested in the situations of their children and be willing to make contact and give instructions on how they could approach them. The biggest concerns of parents were situations in which teachers did not care about their children or their children were not accepted in front of the teacher. Fears of stigma and bad reputations (e.g., of a naughty child or a demanding parent) were clear in the parental interviews.
I-4: [A]nd of course the pupil is more motivated [...] and can manage it and hold on to be there and the approach of teacher is also positive, because that's what I am always afraid of-that because this cooperation is so much about negative things, there is inevitably the feeling of "what if the teacher hates my son because he has such a difficult mother and the boy has those kinds of special needs?"

I-12: [I]f in the work community [teachers and their colleagues], at school is a kind of thought of a boy, that he is a difficult child and this boy is doing that way and everything wrong, then the new teacher, who is coming there, could like filter that all away [...] and not so, that learns to know a child according to stories of other teachers.

According to the parental experiences, the beginning of a teacher-student relationship is very vulnerable. They hoped and aimed to promote the ability of teachers to be in contact with the children, and at the same time, they were worried about their own role in this process. One of the biggest worries was how the teachers reacted if the parents were active. Parents hoped that they could affect and support the position of their children during collaborations. They highlighted the ability of teachers to use the given information.

\section{I-8: It would be very good if the teacher could take into account parents' opinions somehow.}

Parents hoped that teachers could see strengths in each child, and this point of view was sometimes discussed with the children and parents. The positive approach, in general, was evident.

Parents hoped to receive more informative messages from schools alongside the problem-focused reports of situations of their children. They wished to have more information about what teachers and other adults in schools were doing-i.e., how they were taking into account individual characteristics and supporting their children.

Compared with teacher-student and teacher-parent relationships, all other themes, such as hopes to improve the positions of children with their peers, services, and learning goals, represented more of a sidetrack in the interviews.

\section{The Practical-Evaluative Dimension of Agency}

In this dimension, the focus is on the descriptions of the actions and decisions of parents. The roles of parents were changed by contexts during the interviews.

In situations where parents had the opportunity to make contact and take initiative, they informed the schools about their observations at home concerning the school routines of their children. They recognized changes in the behavior of their children and negotiated with teachers about the actions needed. They made contact and received many responses.

I-1: Of course, it felt good when he said that you as a parent are so easy to be in contact with. Well, I talk about things relatively directly, but I say things appropriately, and that's why he gave me this positive feedback. I think things can be discussed as they are. And I have to say what is on my mind. Then we can consider together more [about solutions].

Parents strengthened their ability to collaborate by studying and reading literature about the needs of their children, and 
they had plenty of everyday information about their children to give teachers.

Parents took initiative in multiprofessional processes. They delivered proxy documents and information, dealt with medical or psychological examinations of rehabilitation, and connected with people to maintain and promote the continuum of the multiprofessional network. In schools, the willingness to receive and use information from other professions and take part in and give space for other professions and their contributions was not self-evident. When schools and teachers were able to join and work in multiprofessional collaboration to find solutions, parents were satisfied. The will of teachers to find and try alternative working methods and communicate with support networks to help their children was respected by parents. Parents expressed this by talking about the positive attitudes of teachers, school atmospheres, and their preparedness to teach diverse students.

\section{I-9: Then, for example, the psychologist said that representatives from the school are welcome; they said immediately, "Of course we are coming."}

Parents made "meta-negotiation," meaning negotiating about the possibilities to negotiate more; they build and held together complex networks, including teachers, school transport drivers, therapists, child neurologists, doctors, psychiatric nurses, lawyers, administrative personnel, and school assistants. Usually, the interplay was running rather fluently, but parents were also present in situations where the opinions and conclusions of specialists were strongly contradictory. The experience was at first confusing for parents, but in continuum of negotiations, they had the possibility to learn better how to act in between diverse points of view of specialists. Parents were worrying about the willingness of teachers to collaborate with other professionals. When school personnel at any level were unwilling to negotiate the number of difficulties and contradictions, the situation became complex for parents. However, in meetings and after them, parents had to make sense of fragmented information from different specialists, because they had to deliver information to several other important persons. If the network was large, they had practically no possibility to be present at one time all together.

The parental agency was also connected with processes. Parents were practically responsible for ongoing claims and petitions. The parental agency was directed at multilayered medical processes and administrative processes. If, for example, a child had a new diagnosis, it could lead to a new right to have more out-of-school services, but parents had to fill out applications, collect written expert opinions, and deal with everyday solutions with schools concerning, for example, physical rehabilitation periods during the school day.

The possibility of parents to prepare themselves for the meetings beforehand varied. In some cases, routines were clear and parents were well informed, but there were accounts in which parents could not know what would be the content of the meeting. When there was strong trust between teachers and parents, meetings were fruitful and it was easy to talk about all important things. One element of a good teacherparent relationship was explicit positive information, which led to the active participation of parents and freedom to deliver their agency and share challenges. Unclear information was problematic and hindered the ability of parents to effectively engage in multiprofessional collaboration.

I-14: When we have the IEP meeting, the teacher writes my thoughts. I have has the experience that we are actually collaborating well. The teacher knows my child really well, and after so many years, the IEP is very alike to our son.

I-2: [T] he teacher sent me a note about the meeting - that we should meet about my son's issues and I answered that we are going to have an appointment with a doctor and we are thinking about medication and I think it was about have stronger intensivity to support, I really think [...] maybe it was the reason and the teacher said that we should see at first this, and I should take care of this phase and let's move the meeting to later this year, and this forthcoming meeting, there will maybe be some suggestions about starting special support.

In IEP meetings, there was usually space for parents to discuss their perspectives, and if they were not asked for them, in some situations, parents took initiative and interrupted discussions to voice them.

\section{I-3: I just take my turn to speak, even if it is not really given to me.}

Agency in contradictive situations was connected more or less intensively to own networks of parents. They got support from their families, parents (the grandparents of the child), friends, other parents, and professionals. Negotiations were prepared carefully. Parents collected documents and studied (e.g., juridic points of view and phases of processes) with their peers. Their networks were arenas to consciously reflect on messages, aims, and strategies both before and after meetings.

I-8: I thought that there were too many goals [on teachers' suggestion lists to work with], and I talked about it with someonemaybe a family therapist or something-who visited our home once; and I talked with her, and according to her, it is important to take one thing from there [teachers' suggestion list to work on].

Parents used their agency to balance situations by asking some trusted person to accompany them if they had frustrating experiences at previous meetings. Some parents needed to devise strategies and ways to act. In some cases, they needed someone to help them participate and stay calm in challenging and oppressive situations.

I-6: It needs particular kind of encouragement, that I have strength to go. And we had a kind of strategy, that we are both there together, and sometimes we had grandfather at the meetings to give us a bit more strength.

Even after a strong feeling of worry about the well-being of their children at school, active discussion and initiative from parents can be a good solution to release tension and maintain trust between parents and school as an institution. There were instances where, during interactions, parents recognized that something at school was really wrong. The parents received messages with requests for permission to use unacceptable and inappropriate methods to control the behavior of their children. 
Parents did not accept the requests, and they wanted to take the issue up with headteacher of the school.

I-11: I just informed the school that we absolutely disagree with all physical and fear-based punishments. [...] The headteacher called me and was shocked by the information I gave [...], but I am satisfied by the way things went, and the issue was resolved in a reasonable way.

There were descriptions of differently escalated situations. After trying to take initiative and negotiate and the school refused to discuss, parents asked about the rights of their children by making complaints to Regional State Administrative Agencies, which are governmental enforcement authorities. In an escalated situation, however, the child stayed in the same school. The trust was lost between certain persons, not concerning the school as an institution.

I-13: [A]nd it was last summer when I last tried to kindly asked [sic] if we could one last time sit around the same table, but there was the same list again, and that was the last straw; and then I made several official complaints to the authorities. I filed these templates [complaints] in the legal assistance office, and they had no words. They found the situation outrageous. They could not believe it could happen nowadays in our country.

One possibility for parents in contradictory situations was to give schools negative feedback over by active choice of being in silence. They felt that the continuous flow of e-messages containing only negative feedback and requests to talk with the child about poorly described problematic episodes during school days was frustrating both for themselves and the child. They had no power to stop the negative messages. As a parental choice, they talked about conscious decisions not to act. The aim was to hold their own position as parents. The information they had from the teacher was too narrow and especially they had no information about pedagogical implications at school. They could not solve the contradiction in differences between the version of the child and a short written note from school without discussing school personnel. In that sense, it seems that the trust of parents in teachers and the ability of whole school to treat children and their parents with respect are important elements in cooperation. If the content of information of their own child is entirely negative, the need for parents to consider how negative feedback affects the well-being of their child and how to get along with a very negative educational environment.

\section{DISCUSSION}

The aim of this study is to present the qualitative differences in parental agency during negotiations in school contexts in which a child has special educational needs. The parental voices are connected to local micro-contexts and experiences. Both agency and inclusive culture are based on interaction and participation. The rules of interplay are controlled and defined at schools. In the descriptions of parents, there are no marks of negotiating about chosen tools for interaction. The teacher or the school organization decides the tool according to their preferences. Some teachers used only electronic applications, some preferred the phone, and some email. In situations where the school or teacher is unwilling or unable to negotiate and does not respect or promote parental agency and participation, there is no space for interaction.

The dynamic of parental agency in these interviews develops in relation to individuals, life courses, and contexts (Biesta and Tedder, 2007; Archer, 2010). The qualitative differences between the experienced agencies are relatively united when the parental agency can be delivered in interactions and parents can actively voice their concerns in negotiations. In a meaningful context, parents can speak and participate fully and with trust that all members involved are supportive even if collaborative processes are conflicting, in case there is space for negotiations. Parents can protect their children persistently and simultaneously maintain negotiations.

Although the political process to enhance inclusive education in Finland is progressive and legislation and norms support change, the implications of suggested inclusive practices seem to be more fragile and fragmented. The practices are connected to individual teachers, and parents have to learn each teacher and his or her practices. The parental view to practices at schools provides a contradictory and complex picture of school, and this view can be very confusing. The strategy of parents, in general, is to learn practices teacher by teacher and they try to find appropriate ways to their agentic position as well, teacher by teacher. However, in order to develop the well-being of children at school, in this study parents highlighted the importance to respect the parental experience of their own child. In this sense, findings are equal with Runswick-Cole (2008).

A limitation of this study is that participants were found via networks of parents and snowball sampling. It is possible that active parents are more willing to share their views. In addition, the group of participants raises some questions: Why does education seem to be an area of greater concern for mothers in particular? Several studies concerning education report that parents are presented only as "parents." Often, in researching education, and especially when attendance at research is entirely free, and where the gender of participants is reported, most participants are mothers (e.g., Griffiths et al., 2004; Rogers, 2007; Tucker and Schwartz, 2013; Koskela et al., 2020).

The analysis was executed by one researcher, and this is a limitation. To get feedback on the content and structure of categories, based on pseudonymized quotations, decisions regarding analysis were discussed with colleagues. However, they did not see the whole set of transcriptions. In that sense, the researcher was responsible for the process, interpretations, findings, and conclusions (Malterud, 2001). This approach enabled reporting the fragmentation of experiences present in the data and showing the connection between quotations and interpretations. Quotations were selected to illustrate variations in experiences.

It seems clear that this topic warrants further research. First, the focus group in this research was parents with children who needed support at school and with studying. According to the wider understanding of inclusion (Ainscow et al., 2006; UNESCO, 2018), there is a need to learn about parental agency in general and to collect data concerning all parents. Second, we 
need research with different methods to get more information to follow the progress in developing inclusive practices and to find bias in generalizations. Third, we need to hear the voices of all members of networks of children (e.g., teachers and other professionals) to improve the quality of support and collaboration between all members.

There were no descriptions in interview data of how schools tell parents about their roles, opportunities, and the structure of processes. However, that information is needed in situations where parents and schools are starting to collaborate. It is always needed when a teacher is replaced or if the student has to change school because of family moving to a different neighborhood.

\section{CONCLUSION}

This research describes both grateful and critical parental voices concerning their agency in negotiations focusing on the needs of support for their children in Finnish schools. It also reveals that parents usually have many qualitatively distinct experiences in various social contexts, and it is relevant to discuss previous experiences of parents to promote new supportive processes. Most of all, the research shows how important it is for parents to be treated with respect and as responsible adults. We can discuss qualitative differences in experiences, but we cannot draw conclusions about how prevalent or widespread those experiences are. That is the most important reason to listen to parents as individuals with unique experience backgrounds.

Parental agency is a dynamic phenomenon. It grows and develops along with the children, and it is strongly rooted in the parental interpretations of the school contexts and the family network of their children.

Given the results, several suggestions can be made regarding education. To promote parental agency, schools should keep parents more informed about opportunities to take part in negotiations. It is extremely difficult to find any systematic way in the descriptions of cooperative processes of parents across schools or teachers. It seems that every teacher has own and individual habit to handle processes and parents just have to learn manners and means of every teacher. As a critical point of view, there is a need to consider the nature of parental possibility to implicate active agency in discussions concerning the well-being of their child at school: Is it about "being lucky," as parents say, or if "it depends on teacher," and the process is hardly quality in general. There is a need to discuss, guide, and study collaborative relations and processes more effectively in teacher education, especially in local in-service teacher education. However, the more important group in this sense seems to be leaders at schools. They can develop and strengthen the role of shared practices, and enhance the parental possibility to learn parental agency in supporting their children. Clearly, schools and school environments are diverse; however, to promote better

\section{REFERENCES}

Äärelä, T., Määttä, K., and Uusiautti, S. (2018). The challenges of parent-teacher collaboration in the light of hospital school pedagogy. Early Child Dev. Care 188, 709-722. doi: 10.1080/03004430.2016.1230108 collaboration with parents and to better understand parents, there is a need to develop and strengthen progress toward inclusivity at schools at all levels.

In supporting the well-being of children at school, according to the interview data, there is a strong need for collaboration. School personnel, especially teachers, should be more in touch with parents and should discuss and be aware of a range of parental experiences. Parents should be able to contact the school without being worried about the positions of their children and how teachers see them. It is a matter of experienced trust, and it is very easy to break this trust. Another suggestion to schools and teachers is to pay attention to parents whose children need support. This group of parents is easy to recognize. Open interaction focusing more on pedagogical solutions than difficulties of a child helps parents to trust school personnel.

The most evident concerns of parents were the following: Is my child accepted by the teacher? Does the teacher treat my child as a valuable person? How do I act as a parent to support and maintain the well-being of my child? Being accepted is one of the basic elements of well-being. The willingness of teachers to listen to parents, take their suggestions into account, and openly include them in the collaborative planning process helps parents support teachers in an inclusive school environment.

\section{DATA AVAILABILITY STATEMENT}

The datasets presented in this article are not readily available because of ethical restrictions linked to the interview data. Requests to access the datasets should be directed to TK, teija.koskela@utu.fi.

\section{ETHICS STATEMENT}

Ethical review and approval was not required for the study on human participants in accordance with the local legislation and institutional requirements. Written informed consent for participation was not required for this study in accordance with the national legislation and the institutional requirements.

\section{AUTHOR CONTRIBUTIONS}

The author confirms being the sole contributor of this work and has approved it for publication.

\section{FUNDING}

This study was supported by the Faculty of Education, University of Turku.

Ainscow, M. (2014). "Struggling for equity in education: the legacy of salamanca," in Inclusive Education Twenty Years After Salamanca, eds F. Kiuppis and R. Sarromaa Hausstätter (New York, NY: Peter Lang), 41-55.

Ainscow, M., Booth, T., and Dyson, A. (2006). Improving Schools, Developing Inclusion. New York, NY: Routledge. 
Archer, M. (2010). Routine, reflexivity, and realism. Sociol. Theory 28, 272-302.

Barnes, P. (2008). Multi-agency working: what are the perspectives of SENCos and parents regarding its development and implementation? Br. J. Spec. Educ. 35, 230-240.

Basic Education Act [BEA] (2010). "Ministry of education and culture, Finland. Amendments up to 1136/2010," in Basic Education Act (628/1998). Available online at: https://minedu.fi/en/legislation-general-education (accessed November 16, 2020).

Biesta, G., and Tedder, M. (2007). Agency and learning in the life-course: towards an ecological perspective. Stud. Educ. Adult. 39, 132-149.

Björn, P. M., Aro, M. T., Koponen, T. K., Fuchs, L. S., and Fuchs, D. H. (2016). The many faces of special education within RTI frameworks in the United States and Finland. Learn. Disabil. Q. 39, 58-66. doi: 10.1177/073194871559 4787

Böök, M. L., and Perälä-Littunen, S. (2015). Responsibility in home-school relations - finnish parent's views. Child. Soc. 29, 615-625.

Bryan, J., and Henry, L. (2012). A model for building school-familycommunity partnerships: principles and process. J. Couns. Dev. 90, 408-420.

Chong, P. W. (2018). The finnish "Recipe" towards inclusion: concocting educational equity, policy rigour, and proactive support structures. Scand. J. Educ. Res. 62, 501-518. doi: 10.1080/00313831.2016.1258668

de Boer, A., Pijl, S. J., and Minnaert, A. (2010). Attitudes of parents towards inclusive education: a review of the literature. Eur. J. Spec. Needs Educ. 25, 165-181. doi: 10.1080/08856251003658694

Edwards, A. (2017). "The dialectic of person and practice: how cultural-historical accounts of agency can inform teacher education," in The SAGE Handbook of Research on Teacher education, eds D. J. Clandinin and J. Husu (London: SAGE), 269-285.

Emirbayer, M., and Mische, A. (1998). What is agency? Am. J. Sociol. 103, 9621023.

Engelbrecht, P., Savolainen, H., Nel, M., Koskela, T., and Okkolin, M. (2017). Making meaning of inclusive education: classroom practices in Finnish and South African classrooms. Compare 47, 684-702. doi: 10.1080/03057925.2016. 1266927

Eteläpelto, A., Vähäsantanen, K., Hökkä, P., and Paloniemi, S. (2013). What is agency? Conceptualizing professional agency at work. Educ. Res. Rev. 10, 45-65.

European Agency for Development in Special Needs Education [EADSNE] (2011). Teacher Education for Inclusion Across Europe-Challenges and Opportunities. Odense: European Agency for Development in Special Needs Education.

Finnish National Agency for Education [FNAE] (2016). National Core Curriculum for Basic Education 2014. Publications 2016:5. Helsinki: FNAE.

Finnish National Board on Research Integrity (2009). Humanistisen, Yhteiskuntatieteellisen ja Käyttäytymistieteellisen Tutkimuksen Eettiset Periaatteet ja Ehdotus Eettisen Ennakkoarvioinnin Järjestämiseksi. Available online at: https://www.tenk.fi/sites/tenk.fi/files/eettisetperiaatteet.pdf (accessed 10.11.2020)

Giddens, A. (1984). The Constitution of Society?: Outline of the Theory of Structuration. Cambridge: Polity.

Griffiths, C. B., Norwich, B., and Burden, B. (2004). Parental agency, identity and knowledge: mothers of children with dyslexia. Oxf. Rev. Educ. 30, 417-433.

Grillitsch, M., and Sotarauta, M. (2020). Trinity of change agency, regional development paths and opportunity spaces. Prog. Hum. Geogr. 44, 704-723. doi: $10.1177 / 0309132519853870$

Halinen, I., and Järvinen, R. (2008). Towards inclusive education: the case of Finland. Prospects 38, 77-97. doi: 10.1007/s11125-008-9061-2

Hartas, D. (2008). Practices of parental participation: a case study. Educ. Psychol. Pract. 24, 139-153.

Hein, N. (2017). New perspectives on the positioning of parents in children's bullying at school. Br. J. Sociol. Educ. 38, 1125-1138. doi: 10.1080/01425692. 2016.1251305

Honkasilta, J., Vehkakoski, T., and Vehmas, S. (2015). Power struggle, submission and partnership: agency constructions of mothers of children with ADHD diagnosis in their narrated school involvement. Scand. J. Educ. Res. 59, 674-690. doi: 10.1080/00313831.2014.965794
Hotulainen, R., and Takala, M. (2014). Parents' views on the success of integration of students with special education needs. Int. J. Incl. Educ. 18, 140-154. doi: $10.1080 / 13603116.2012 .759630$

Illsley, P., and Redford, M. (2005). 'Drop in for Coffee': working with parents in North Perth New Community Schools. Support Learn. 20, 162-166.

Knibbe, M., and Horstman, K. (2019). Constructing democratic participation in welfare transitions: an analysis of narrative interactions. Health Expect. 23, 84-95. doi: 10.111/hex.12970

Koskela, T., Pihlainen, K., Piispa-Hakala, S., Vornanen, R., and Hämäläinen, J. (2020). Parents' views on family resiliency in sustainable remote schooling during the COVID-19 outbreak in Finland. Sustainability 21:8844. doi: 10.3390/ su12218844

Kozleski, E., and Waitoller, F. (2010). Teacher learning for inclusive education: understanding teaching as a cultural and political practice. Int. J. Incl. Educ. 14, 655-666.

Kozleski, E. B., Artiles, A. J., Fletcher, T., and Engelbrecht, P. (2009). Understanding the dialectics of the local and the global in education for all: a comparative case study. Int. Crit. Child. Policy Stud. J. 2, 15-29.

Lucas, S. (2019). The assembly of active participation by parents of children subject to a multi-agency model of early intervention in child and family services. Child .Fam. Soc. Work 24, 529-536. doi: 10.1111/cfs.12633

Malterud, K. (2001). Qualitative research: standards, challenges, and guidelines. Lancet 358, 483-488. doi: 10.1016/S0140-6736(01)05627-6

Marton, F., and Booth, S. (1997). Learning and Awareness. Mahwah: Lawrence Erlbaum.

Michael, S., Dittus, P., and Epstein, J. (2007). Family and community involvement in schools: results from the school health policies and programs study 2006. J. Sch. Health 77, 567-587.

Mitchell, D. (2012). Joined Up: A Comprehensive, Ecological Model for Working with Children with Complex Needs and Their Families/Whanau. Available online at: https://education.govt.nz/assets/Documents/Ministry/consultations/ Residential-Special-Schools-consultation/JoinedUp.pdf (accessed 10.11.2020).

Mitchell, D. (2014). What Really Works in Special and Inclusive Education. Using Evidence Based Teaching Strategies. London: Routledge.

Official Statistics of Finland [OSF] (2020). Special Education [e-publication].ISSN=1799-1617. 2019. Helsinki: Statistics Finland.

Okkolin, M.-A., Koskela, T., Engelbrecht, P., and Savolainen, H. (2018). Capability to be educated-inspiring and inclusive pedagogical arrangements from finnish schools. J. Hum. Dev. Capab. 19, 421-437. doi: 10.1080/19452829.2018.1474858

Payne, K., and Zeichner, K. (2017). "Multiple voices and participants in teacher education," in The SAGE Handbook of Research on Teacher Education, eds D. J. Clandinin and J. Husu (London: SAGE), 1101-1116.

Rautamies, E., Vähäsantanen, K., Poikonen, P.-L., and Laakso, M.-L. (2016). Teacher-child relationships narrated by parents of children with difficulties in self-regulation. Early Child Dev. Care 186, 1846-1858. doi: 10.1080/03004430. 2015.1135429

Rautamies, E., Vähäsantanen, K., Poikonen, P.-L., and Laakso, M.-L. (2019). Parental agency and related emotions in the educational partnership. Early Child Dev. Care 189, 896-908. doi: 10.1080/03004430.2017.1349763

Rogers, C. (2007). Experiencing an 'inclusive' education: parents and their children with 'special educational needs. Br. J. Sociol. Educ. 28, 55-68. doi: 10.1080/ 01425690600906659

Runswick-Cole, K. (2008). Between a rock and a hard place: parents' attitudes towards to the inclusion of children with special educational needs in mainstream and special schools. Br. J. Spec. Educ. 35, 173-180.

Savolainen, H. (2009). Responding to diversity and striving for excellence: the case of Finland. Prospects 39, 281-292. doi: 10.1007/s11125-009-9125-y

Sin, S. (2010). Considerations of quality in phenomenographic research. Int. J. Qual. Methods 9, 305-319.

Takala, M., Sarromaa Haussttätter, R., Ahl, A., and Headd, G. (2012). Inclusion seen by student teachers in special education: differences among Finnish, Norwegian and Swedish students. Eur. J. Teach. Educ. 35, 305-325.

Thomas, G. (2013). A review of thinking and research about inclusive education policy, with suggestions for a new kind of inclusive thinking. Br. Educ. Res. J. 39, 473-490.

Tucker, V., and Schwartz, I. (2013). Parents' perspectives to collaboration with schools professionals: barriers and facilitators to successful partnerships in 
planning for students with ASD. School Ment. Health 5, 3-14. doi: 10.1007/ s12310-012-9102-0

Tveit, A. D. (2009). A parental voice: parents as equal and dependent rhetoric about parents, teachers, and their conversations. Educ. Rev. 61, 289-300.

UNESCO (2018). Concept Note for the 2020 Global Education Monitoring Report on Inclusion. Paris: UNESCO.

United Nations (2015). The 2030 Agenda for Sustainable Development. Available online at: https://sustainabledevelopment.un.org/content/documents/ $21252030 \% 20$ Agenda\%20for\%20Sustainable\%20Development\%20web.pdf (accessed 10.11.2020).

Väyrynen, S., and Paksuniemi, M. (2020). Translating inclusive values into pedagogical actions. Int. J. Incl. Educ. 24, 147-161. doi: 10.1080/13603116.2018. 1452989
Vetoniemi, J., and Kärnä, E. (2019). Being included - experiences of social participation of pupils with special education needs in mainstream schools. Int. J. Incl. Educ. 1-15. doi: 10.1080/13603116.2019.1603329

Conflict of Interest: The author declares that the research was conducted in the absence of any commercial or financial relationships that could be construed as a potential conflict of interest.

Copyright ( $(2021$ Koskela. This is an open-access article distributed under the terms of the Creative Commons Attribution License (CC BY). The use, distribution or reproduction in other forums is permitted, provided the original author(s) and the copyright owner(s) are credited and that the original publication in this journal is cited, in accordance with accepted academic practice. No use, distribution or reproduction is permitted which does not comply with these terms. 